\title{
ACTIVITY OF THE MEDICINAL PLANT PARKIA JAVANICA AGAINST MULTIDRUG-RESISTANT NEISSERIA GONORRHOEAE AND OTHER CLINICAL ISOLATES
}

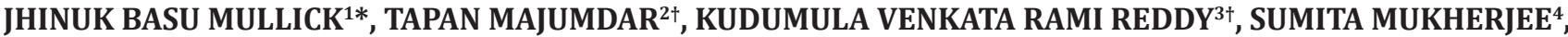 \\ SAMIR KUMAR SIL ${ }^{1 *}$
}

${ }^{1}$ Molecular Genetics and Cell Physiology Lab, Department of Human Physiology, Tripura University, Agartala, Tripura, India. ${ }^{2}$ Department of Microbiology, Agartala Government Medical College, Agartala, Tripura, India. ${ }^{3}$ Division of Molecular Immunology and Microbiology, National Institute for Research in Reproductive Health, Mumbai, Maharashtra, India. ${ }^{4}$ Department of Respiratory Diseases, Agartala Government Medical College, Agartala, Tripura, India. Email: s_k_sil@yahoo.com $\dagger$ These authors contributed equally to this work.

Received: 18 April 2019, Revised and Accepted: 05 July 2019

ABSTRACT

Objective: The objective of this study was to look into the in vitro activity of Parkia javanica against isolates of Neisseria gonorrhoeae.

Methods: Methanolic extract of P. javanica bark (MEPJ) and organic fractionation were tested against one standard strain and 10 clinical isolates including one multidrug-resistant (MDR) isolate of $N$. gonorrhoeae through minimum inhibitory concentrations (MIC) and minimum bactericidal concentrations (MBC) tests.

Results: The MDR isolate, standard strain, as well as all the clinical isolates were inhibited by MEPJ as well as all the fractions except water fraction. Chloroform fraction showed the best activity with MIC and MBC values, both being $0.2 \mathrm{mg} / \mathrm{ml}$. Ethyl acetate fraction also showed MIC value at $0.2 \mathrm{mg} / \mathrm{ml}$; however, MBC value was at $0.3 \mathrm{mg} / \mathrm{ml}$. MIC and MBC values of MEPJ were both $0.3 \mathrm{mg} / \mathrm{ml}$.

Conclusion: Chloroform fraction, ethyl acetate fraction, and MEPJ bark showed the lowest MIC values and can be considered as prospective candidates for the development of antigonococcal topical drugs.

Keywords: Medicinal plants, Parkia javanica (Lam.) Merr., Neisseria gonorrhoeae, Multidrug resistance, Organic fractions, Minimum inhibitory concentrations, Minimum bactericidal concentrations.

(C) 2019 The Authors. Published by Innovare Academic Sciences Pvt Ltd. This is an open access article under the CC BY license (http://creativecommons. org/licenses/by/4. 0/) DOI: http://dx.doi.org/10.22159/ajpcr.2019.v12i9.33654

\section{INTRODUCTION}

All living organisms including plants have innate mechanisms to defend themselves against invading pathogens, which may be targeted to particular attackers, or generalized for diverse pathogens from insects to bacteria and fungi [1]. Before the invention of synthetic drugs and antibiotics, man had to rely on these active natural products mostly from plants, microbes, and other animals [2]. As per the World Health Organization estimation, even today $65-80 \%$ of the world population relies on herbal medicines [3] which are eco-friendly, natural and have lesser chances of giving adverse drug reactions and resistance [4].

Gonorrhea is a sexually transmitted infection (STI) causing urethral or cervical discharge and ocular, pharyngeal, and anorectal infections [5]. Worldwide, an estimated 62 million new infections of gonorrhea occur annually [6], making it the second most common STI. The infectious agent, Neisseria gonorrhoeae remains asymptomatic in as high as $55 \%$ of men and $86 \%$ of women [7]. Untreated gonorrhea is a problem, causing pelvic inflammatory disease and infertility in women [8], and prostate cancer in men [9]. N. gonorrhoeae can also increase HIV-1 transmission by $500 \%$ [10]. Once an easily curable disease, gonorrhea has become a major problem due to drug resistance and cross-resistance.

Parkia javanica (Lamk.) Merr. (Synonyms: Parkia roxburghii G. Don, Parkia timoriana (DC.) Merr.) belonging to the family Mimosaceae is a medicinal plant well distributed in India and Southeast Asia [11]. It is a multipurpose tree being used as an insecticide, pesticide, human food, and cosmetic purposes [11]. Medicinally, it is used for stomach problems such as stomach ache and cholera [12], diarrhea, dysentery, and food poisoning [13]. Tribal people of Tripura use its extract to cure wounds and scabies [14]. With its widely suited applications and activity against standard Gram-positive and Gram-negative bacteria [15], we wanted to look into the in vitro activity of $P$. javanica on locally circulating clinical isolates of $N$. gonorrhoeae.

\section{MATERIALS AND METHODS}

Plant material

Fresh barks of $P$. javanica were collected from the Tripura University Campus at Suryamaninagar, Agartala, Tripura, during December 2015. For ensuring correct botanical identification, the plant was cross-verified by Prof. B. K. Datta, Taxonomist, Department of Botany, Tribhuvan University, and a herbarium specimen (\#BD-01/06) was deposited in the Central National Herbarium, Botanical Garden, Shibpur, Howrah, West Bengal, India.

\section{Preparation of extract}

Barks of $P$. javanica were washed and air-dried for 3 weeks. They were then chopped into smaller pieces and partially ground with mortar and pestle. Around $200 \mathrm{~g}$ of ground bark was macerated with $600 \mathrm{ml}$ of methanol at room temperature for $48 \mathrm{~h}$. Next, the decanted extract was filtered through Whatman filter paper 4 and evaporated in a rotary evaporator (Hahn Shin Scientific Corporation, South Korea). At the end of this, methanolic extract of $P$. javanica bark (MEPJ) was left to air dry for a week at $4^{\circ} \mathrm{C}$ to remove traces of the solvent. Similarly, organic fractionation was carried out by extracting successively with $600 \mathrm{ml}$ of different polarity-based solvents, which were chloroform, ethyl acetate, $n$-butanol, methanol, and water. Percentage recovery was calculated as per the method of Anokwuru et al. [16] using the formulae: 
$\%$ recovery $=\frac{\text { Amount of pure product recovered }(\mathrm{g})}{\text { Amount of crude material used }(\mathrm{g})} \times 100$

The final products were dissolved in 25\% DMSO in water to give a stock of $100 \mathrm{mg} / \mathrm{ml}$. Concentrations used in the study were $0.05,0.1,0.2,0.3$, 0.6 , and $1.2 \mathrm{mg} / \mathrm{ml}$.

Identification, isolation, culturing, and antimicrobial susceptibility testing (AST) of clinical isolates of $N$. gonorrhoeae

The institutional ethical committee clearance was obtained before collection of urethral discharge from consented male symptomatic subjects. Of each specimen, direct Gram stain was observed and cultured on chocolate agar as previously described [17]. Confirmatory tests were colony characteristics, Grams staining reactions, biochemical tests, and sugar assimilation tests, which were done as per standard protocol. AST through E test was tested against penicillin G, tetracycline, ciprofloxacin, nalidixic acid, azithromycin, spectinomycin, and ceftriaxone on CA without supplements as per Clinical and Laboratory Standards Institute guidelines [18]. E-strips were obtained from HiMedia Laboratories, Mumbai, India. One quality control (ATCC ${ }^{\circledR} 49226^{\mathrm{TM}}$ ) strain and 10 clinical isolates including one multidrugresistant (MDR) strain were tested against MEPJ and P. javanica fractions. The isolates were stored at $-80^{\circ} \mathrm{C}$ for long-term storage.

Determination of the minimum inhibitory concentration (MIC)

MIC of MEPJ and $P$. javanica fractions was determined against the isolates of $N$. gonorrhoeae as per the previous protocol [19]. Briefly, double dilutions of the extract in deionized water in $100 \mu$ l aliquots were placed in 96-well plates. To this, $140 \mu \mathrm{l}$ of Mueller-Hinton broth and $10 \mu \mathrm{l}$ of $N$. gonorrhoeae isolate were added and incubated at $37^{\circ} \mathrm{C}$ for $16-18 \mathrm{~h}$ in a candle jar. Organism growth was assayed by the measurement of OD600 on a Synergy H1 microplate reader (BioTek, USA). The MIC value $(\mathrm{mg} / \mathrm{ml}$ ) was expressed as the lowest concentration that inhibited $99.99 \%$ of bacterial growth.

Determination of minimum bactericidal concentration (MBC) MBC was determined as per the protocol of Oliveira et al. [20] the extract at the MIC and two above and one below concentrations were subcultured onto chocolate agar plates and incubated for $48 \mathrm{~h}$. MBC $(\mathrm{mg} / \mathrm{ml})$ was determined as the lowest concentration of the extract that prevented more than $99.99 \%$ microbial growth.

\section{RESULTS}

Table 1 shows the final yields which were obtained when initial $200 \mathrm{~g}$ of ground bark was macerated with $600 \mathrm{ml}$ of respective solvent. Based on the yield, the percentage recovery was calculated. Crude methanolic extract (MEPJ) had the highest percentage recovery. Percentage recovery among the fractions was found to increase with increase in polarity of the solvent. Physical characteristic of the crude and each fraction is also noted in Table 1.

Antibacterial activity of $P$. javanica was tested against 10 clinical isolates of $N$. gonorrhoeae and one standard ATCC strain. Susceptibility of each strain to standard drugs is shown in Table 2. An MDR isolate as per the criteria previously described [21] was also included in the study.

The MDR strain which was resistant to spectinomycin, azithromycin, fluoroquinolones drugs, and tetracycline was found to be inhibited by MEPJ as well as all the fractions except water fraction. The other strains as well as the standard strain ATCC $^{\circledR} 49226^{\mathrm{TM}}$ were also inhibited. Activities of MEPJ as well as the fractions against all the 11 isolates were comparable. Fig. 1 shows the antibacterial activity of MEPJ and organic fractions against the isolates. As the percentage inhibition curves show, MIC concentrations ranged between 0.2 and $0.6 \mathrm{mg} / \mathrm{ml}$.

MEPJ, chloroform fraction, and ethyl acetate fractions showed good activity against all the isolates with chloroform fraction showing the best activity with MIC (Fig. 1) and MBC (Table 3) values both being $0.2 \mathrm{mg} / \mathrm{ml}$. Ethyl acetate fraction also showed MIC value at $0.2 \mathrm{mg} / \mathrm{ml}$; however, MBC value was a dilution higher, at $0.3 \mathrm{mg} / \mathrm{ml}$. MIC and MBC values of MEPJ were both $0.3 \mathrm{mg} / \mathrm{ml}$. Although n-butanol fraction inhibited isolates at $0.3 \mathrm{mg} / \mathrm{ml}$, its MBC concentration was found to be $0.6 \mathrm{mg} / \mathrm{ml}$. Inhibitory activity of methanol fraction was also strong but not stronger than that of the previously mentioned extracts. Water fraction showed very high MIC values of $>1.2 \mathrm{mg} / \mathrm{ml}$, indicating limited antibacterial activity.

\section{DISCUSSION}

P. javanica was selected based on ethnobotanical data on the use of the plant among local tribes and people of Northeast India for medicinal purposes. The previous work from our laboratory showed its activity

Table 1: Yield of Parkia javanica crude methanolic extract of stem bark (MEPJ) and various organic fractions

\begin{tabular}{|c|c|c|c|c|c|}
\hline \multicolumn{6}{|c|}{ Initial dry weight used: $200 \mathrm{~g}$} \\
\hline Solvent & Solvent volume & Rotary evaporator temperature & Yield (g) & Recovery (\%) & Physical appearance \\
\hline MEPJ & $600 \mathrm{ml}$ & $70^{\circ} \mathrm{C}$ & 30 & 15 & Deep brown powdery mass \\
\hline Ethyl acetate & & $80^{\circ} \mathrm{C}$ & 0.29 & 0.145 & Light brown powdery mass \\
\hline n-Butanol & & $120^{\circ} \mathrm{C}$ & 1.82 & 0.91 & Light golden powdery mass \\
\hline Methanol & & $70^{\circ} \mathrm{C}$ & 5.68 & 2.84 & Deep brown powdery mass \\
\hline Water & & $100^{\circ} \mathrm{C}$ & 18 & 9 & Deep brown muddy mass \\
\hline
\end{tabular}

MEPJ: Methanolic extract of Parkia javanica

Table 2: Antibiotic susceptibility profile of the clinical isolates toward recommended drugs

\begin{tabular}{|c|c|c|c|c|c|c|}
\hline Neisseria gonorrhoeae clinical isolates & Ceftriaxone & Spectinomycin & Azithromycin & Penicillins & Fluoroquinolones & Tetracyclines \\
\hline Isolate 1 & $\mathrm{~S}$ & S & $\mathrm{S}$ & $S$ & $\mathrm{~S}$ & $\mathrm{~S}$ \\
\hline Isolate 2 (MDR) & $\mathrm{S}$ & $\mathrm{R}$ & $\mathrm{R}$ & S & $\mathrm{R}$ & $\mathrm{R}$ \\
\hline Isolate 3 & $\mathrm{~S}$ & $\mathrm{~S}$ & $\mathrm{~S}$ & $\mathrm{R}$ & $\mathrm{R}$ & $\mathrm{R}$ \\
\hline Isolate 4 & $\mathrm{~S}$ & S & S & S & $\mathrm{R}$ & $\mathrm{S}$ \\
\hline Isolate 5 & $\mathrm{~S}$ & S & $\mathrm{S}$ & S & $\mathrm{S}$ & $\mathrm{S}$ \\
\hline Isolate 6 & $\mathrm{~S}$ & $\mathrm{~S}$ & $\mathrm{~S}$ & $\mathrm{R}$ & $\mathrm{R}$ & $\mathrm{R}$ \\
\hline Isolate 7 & $\mathrm{~S}$ & S & $\mathrm{R}$ & $\mathrm{R}$ & $\mathrm{R}$ & $\mathrm{R}$ \\
\hline Isolate 9 & $\mathrm{~S}$ & S & $\mathrm{S}$ & $\mathrm{R}$ & $\mathrm{R}$ & $\mathrm{S}$ \\
\hline Isolate 10 & $\mathrm{~S}$ & $\mathrm{~S}$ & $\mathrm{~S}$ & $\mathrm{R}$ & $\mathrm{S}$ & $\mathrm{R}$ \\
\hline $\mathrm{ATCC}^{\circledR} 49226^{\mathrm{TM}}$ & $\mathrm{S}$ & S & $\mathrm{S}$ & S & S & $\mathrm{S}$ \\
\hline
\end{tabular}

${ }^{*}$ A single isolate (Isolate 2) showed multidrug resistance (MDR). ${ }^{\dagger} \mathrm{S}$ : Susceptible, R: Resistant 


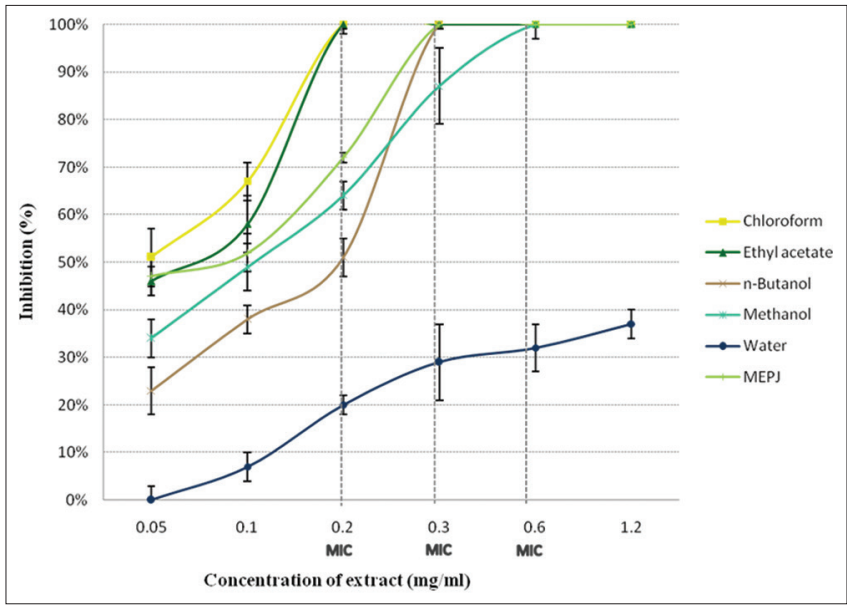

Fig. 1. Concentration-dependent inhibition of Neisseria gonorrhoeae by methanolic extract of Parkia javanica and various organic fractions. The activity was expressed as percentage inhibition. Each point represents mean \pm standard deviation values obtained from 10 clinical isolates and one standard strain

Table 3: Antimicrobial potential of MEPJ and various organic fractions by MIC and MBC assays on Neisseria gonorrhoeae isolates

\begin{tabular}{llll}
\hline \multirow{2}{*}{ Crude extract } & MEPJ & MIC $(\mathbf{m g} / \mathbf{m l})$ & MBC $(\mathbf{m g} / \mathbf{m l})$ \\
\cline { 3 - 4 } & & $\mathbf{0 . 3}$ & $\mathbf{0 . 3}$ \\
\hline Organic fractions & Chloroform & 0.2 & 0.2 \\
& Ethyl acetate & 0.2 & 0.3 \\
& n-Butanol & 0.3 & 0.6 \\
& Methanol & 0.6 & 0.6 \\
& Water & $>1.2$ & $>1.2$ \\
\hline
\end{tabular}

* MIC and MBC $(\mathrm{mg} / \mathrm{ml})$ were determined as the lowest concentration of extract that prevented more than $99.99 \%$ bacterial growth. The data were derived from representative values of 10 clinical isolates and one standard strain. MEPJ: Methanolic extract of Parkia javanica, MIC: Minimum inhibitory concentration, MBC: Minimum bactericidal concentration

against standard Gram-positive and Gram-negative organisms [15] and the parasite Leishmania donovani [22].

The phonological age of a plant plays a major role in determining the distribution of secondary metabolites [23]. The plant from which barks in this study were collected was luckily producing rich amount of active principles. It can also be that $P$. javanica produces active principles all through its different stages of life. P. javanica being a tree, the chances of the presence of secondary metabolites were higher since active principles are found in higher concentrations in woody plants contributing to herbivore avoidance strategy [24].

Chloroform fraction, ethyl acetate fraction, and MEPJ showed the lowest MIC values of $200 \mu \mathrm{g}, 300 \mu \mathrm{g}$, and $300 \mu \mathrm{g}$, respectively, and can be considered as prospective candidates for microbicide development. These MIC values were much higher than those reported in similar studies $[25,26]$. The MIC concentrations observed in our study were, however, lower than those reported by Kuete et al.[27].

P. javanica is one of the costliest vegetables in Northeast India and its application in traditional medicine, face wash and shampoo, and to heal wounds [11] implies that the plant possibly has little to no toxicity, though this is a subject of future research.

In our study, the organic fractions of $P$. javanica showed reduction in activity in the order that they were fractionated. The best antibacterial activity against $N$. gonorrhoeae isolates was observed in the chloroform fraction, followed by the ethyl acetate fraction, n-butanol fraction, methanol fraction, and water fraction. Similar studies of antimicrobial activity by other plant extracts have also shown decrease in activity with increase in polarity $[28,29]$. The order in which the organic solvents were used for extraction could explain that the active ingredients were more lipophilic. The free radical scavenging potential of other plant extract studies [30] has been found in the order of chloroform >ethyl acetate $>$ n-butanol and could explain the antimicrobial potential observed in the current study. The possibility of the presence of impurities with increase in polarity could also be a reason which has diluted the concentration of active ingredients in more polar organic fractions.

The standard drugs recommended for treatment, which are ceftriaxone and spectinomycin, however, exhibited better MIC values against $N$. gonorrhoeae, both clinical isolates and the laboratory standard. This was expected due to the presence of various impurities in MEPJ extract and organic fractions. The MDR strain, however, could not be inhibited by spectinomycin; where as MEPJ and most of the fractions inhibited the strain at low concentrations. This shows that if further purification and isolation can be done to obtain the active antimicrobial ingredients present in P. javanica, it is to be expected that the inhibitory and bactericidal values will be in much lower range and comparable to purified molecules present in synthetic drugs.

Drawbacks of the study and all studies related to plant extracts, in general, are the season of collection, phenological age of the plant, climatic, and abiotic factors since determining the ideal conditions and controlling external factors can be difficult. Since batch-to-batch variations affect the presence of secondary metabolites, in the present study, we collected the raw material in one batch sufficient to prepare the crude extract as well as the fractions. Future studies on P. javanica should be focused on methods to identify antimicrobial molecules, which can avoid such problems as batch-to-batch variations and also pure compounds can be expected to be effective at much lower concentrations.

\section{CONCLUSION}

$P$. javanica was effective in inhibiting $N$. gonorrhoeae. The plant was able to inhibit MDR clinical isolate as well as other clinical isolates and standard strain of $N$. gonorrhoeae. MEPJ, the crude methanolic extract of the bark of $P$. javanica, and most of the fractions obtained through successive extraction with the various solvents were effective in inhibiting the bacteria, except for the water fraction. Chloroform fraction, ethyl acetate fraction, and MEPJ were the most effective with the lowest MIC values being $200 \mu \mathrm{g}, 300 \mu \mathrm{g}$, and $300 \mu \mathrm{g}$, respectively. These extracts can, therefore, be considered to be developed into antigonococcal topical drugs. The dosage may be further reduced if the active antimicrobial compounds can be identified and isolated in future.

\section{ACKNOWLEDGMENT}

This study was supported by the Department of Biotechnology under the Ministry of Science and Technology, India (DBT Sanction Order No.: BT/241NE/TBP/2011, Dated: 30/04/2012). The authors thank Prof. Badal Kumar Datta, for his help with the identification of $P$. javanica plant. The authors also thank HiMedia Laboratories for providing with $N$. gonorrhoeae strain ATCC ${ }^{\circledR} 49226^{\mathrm{TM}}$.

\section{AUTHORS' CONTRIBUTIONS}

The concept of the study was of Prof. Samir Kumar Sil, Dr. KVR Reddy, Dr. Tapan Majumdar, and Prof. Sumita Mukherjee. Jhinuk Basu Mullick was involved in clinical and experimental studies and data acquisition. All the authors contributed equally to study design, literature search, data analysis, manuscript preparation, and review.

\section{CONFLICTS OF INTEREST}

The authors declare that they have no conflicts of interest. 


\section{REFERENCES}

1. Mishra N, Behal KK. Antimicrobial activity of some spices against selected microbes. Int J Pharm Pharm Sci 2010;2:187-96.

2. Raj T, Kumar P, Rathee R, Dubey KK. Screening of some medicinal plants for their antimicrobial activities. Int J Pharm Pharm Sci 2016;8:202-6.

3. Verma S, Singh SP. Current and future status of herbal medicines. Vet World 2008;2:347-50.

4. Mundy L, Pendry B, Rahman M. Antimicrobial resistance and synergy in herbal medicine. J Herb Med 2016;6:53-8.

5. Mayor MT, Roett MA, Uduhiri KA. Diagnosis and management of gonococcal infections. Am Fam Physician 2012;86:931-8.

6. Brookings C, Goldmeier D, Sadeghi-Nejad H. Sexually transmitted infections and sexual function in relation to male fertility. Korean J Urol 2013;54:149-56

7. Korenromp EL, Sudaryo MK, de Vlas SJ, Gray RH, Sewankambo NK, Serwadda D, et al. What proportion of episodes of gonorrhoea and chlamydia becomes symptomatic? Int J STD AIDS 2002;13:91-101.

8. Pavletic AJ, Wölner-Hanssen P, Paavonen J, Hawes SE, Eschenbach DA. Infertility following pelvic inflammatory disease. Infect Dis Obstet Gynecol 1999; 7:145-52.

9. Caini S, Gandini S, Dudas M, Bremer V, Severi E, Gherasim A, et al. Sexually transmitted infections and prostate cancer risk: A systematic review and meta-analysis. Cancer Epidemiol 2014;38:329-38.

10. Chen A, Boulton IC, Pongoski J, Cochrane A, Gray-Owen SD. Induction of HIV-1 long terminal repeat-mediated transcription by Neisseria gonorrhoeae. AIDS 2003;17:625-8

11. Sahoo UK. Parkia roxburghii: An underutilized but multipurpose tree species for reclamation of jhum land. Curr Sci 2013;104:1598-99.

12. Majumder K, Dutta BK, Roy D. Inventory and status of medicinal trees of Tripura. In: Trivedi PC, editor. Indian Medicinal Plants. Jaipur: Avishkar publishers, Distributor; 2009. p. 93-123.

13. Sinha SC. Medicinal Plants of Manipur. Manipur Association for Science and Society (MASS). Calcutta: (Manipur Cultural Integration Conference (MCIC) Publishers, Palace Compound, Imphal), Manasi Printers; 1996.

14. Bhardwaj S, Gakhar SK. Ethnomedicinal plants used by the tribals of Mizoram to cure cuts and wounds. Indian J Tradit Knowl 2005;4:75-80.

15. Saha R, Sil SK, Mohanta B, Dinda B. Antibacterial activity of Parkia javanica an indigenous medicinal plant of Tripura. J Ecotoxicol Environ Monit 2007; 17:15-9.

16. Anokwuru CP, Anyasor GN, Ajibaye O, Fakoya O, Okebugwu P. Effect of extraction solvents on phenolic, flavonoid and antioxidant activities of three Nigerian medicinal plants. Nat Sci 2011;9:53-61.
17. Bala M, Mullick JB, Muralidhar S, Kumar J, Ramesh V. Gonorrhoea and its co-infection with other ulcerative, non-ulcerative sexually transmitted and HIV infection in a regional STD Centre. Indian J Med Res 2011;133:346-9.

18. Clinical and Laboratory Standards Institute. Method for Antifungal Disk Diffusion Susceptibility Testing of Yeasts; Approved GuidelinesSecond Edition. Vol. 29. CLSI Document M44-A2; 2009.

19. Casteels P, Ampe C, Jacobs F, Tempst P. Functional and chemical characterization of Hymenoptaecin, an antibacterial polypeptide that is infection-inducible in the honeybee (Apis mellifera). J Biol Chem 1993;268:7044-54.

20. Oliveira DA, Salvador AA, Smânia A Jr., Smânia EF, Maraschin M, Ferreira SR, et al. Antimicrobial activity and composition profile of grape (Vitis vinifera) pomace extracts obtained by supercritical fluids. J Biotechnol 2013;164:423-32.

21. Bala M, Sood S. Cephalosporin resistance in Neisseria gonorrhoeae. J Glob Infect Dis 2010;2:284-90.

22. Saha R, Basu JM, Roy S, Dinda B, Sil SK. In vitro activity of Parkia javanica extract against Leishmania donovani parasite. J Appl Biosci 2010;36:85-9.

23. Achakzai AK, Achakzai P, Masood A, Kayani SA, Tareen RB. Response of plant parts and age on the distribution of secondary metabolites in plants found in Quetta. Pak J Bot 2009;41:2129-35.

24. Skarpe C, Hester AJ. Plant traits, browsing and grazing herbivores, and vegetation dynamics. In: Gordon IJ, Prins HH, editors. The Ecology of Browsing and Grazing. Ecological Studies. Vol. 195. Berlin, Heidelberg: Springer; 2008. p. 217-61

25. Otto RB, Ameso S, Onegi B. Assessment of antibacterial activity of crude leaf and root extracts of Cassia alata against Neisseria gonorrhea. Afr Health Sci 2014;14:840-8.

26. Doughari JH, El-mahmood AM, Tyoyina I. Antimicrobial activity of leaf extracts of Senna obtusifolia (L). Afr J Pharm Pharm 2008;2:7-13.

27. Kuete V, Wabo GF, Ngameni B, Mbaveng AT, Metuno R, Etoa FX, et al. Antimicrobial activity of the methanolic extract, fractions and compounds from the stem bark of Irvingia gabonensis (Ixonanthaceae). J Ethnopharmacol 2007;114:54-60.

28. Alam MT, Karim MM, Khan SN, Antibacterial activity of different organic extracts of Achyranthes aspera and Cassia alata. J Sci Res 2009;1:393-8.

29. El-Mahmood AM, Doughari JH. Phytochemical screening and antibacterial evaluation of the leaf and root extracts of Cassia alata (Linn). Afr J Pharm Pharm 2008;2:124-9.

30. Hossain MA, Shah MD, Gnanaraj C, Iqbal M. In vitro total phenolics, flavonoids contents and antioxidant activity of essential oil, various organic extracts from the leaves of tropical medicinal plant Tetrastigma from Sabah. Asian Pac J Trop Med 2011;4:717-21. 